\title{
Financial and non-financial risk attitudes: what does it matter?
}

\author{
Annarita Colasante ${ }^{1}$ and Luca Riccetti ${ }^{2}$ \\ ${ }^{1}$ University Jaume I, Economics Department, Avenida de Sos Baynat, 12071 Castellon de la Plana (Spain) \\ ${ }^{2}$ University of Macerata, Economics and Law Department, via Crescimbeni 14, 62100 Macerata (Italy). Telephone \\ number: +3907332583276. E-mail: luca.riccetti@unimc.it. Corresponding author.
}

\begin{abstract}
In this paper we try to: (i) study the personal features of the subjects that can influence the risk attitude in financial and non-financial contexts, (ii) understand the correspondences among some behaviors in financial and non-financial choices. We start from the questionnaire used by Colasante and Riccetti (2020), that investigates how subjects take into account the first four moments of the return distribution in making risky decisions, and that collects data from a very large and heterogeneous population. We find that age and geographical location are important determinants of risk propensity in all domains. Moreover, we find that risk attitudes in financial and non-financial contexts are correlated, but correlation is far from 1, with a larger risk aversion in non-financial contexts. Therefore, there is a common underlying risk trait, but the context is also relevant. Interestingly, the financial risk propensity is positively correlated to the propensity to perform illegal activities.
\end{abstract}

Keywords: experiment, choice under uncertainty, behavioral finance, moments of return distribution, demographics.

JEL classification codes: C91, D01, D81, D90, G40.

Declarations of interest: none. 


\section{Introduction}

A very relevant topic, because of its implications in understanding the behavior of subjects, is the risk attitude. In the economic literature, the problem is often faced as a problem of a monetary choice under uncertainty, associating the concepts of uncertainty and risk. Such choices are often modeled by economists and practitioners under the assumptions that: (i) subjects are rational utility maximizer (the first and widely accepted theory to formalize and explain this kind of decision is the Expected Utility Theory - EU, hereafter - axiomatized by von Neumann and Morgensten, 1947); (ii) the utility is a function of the expected mean and variance of the return distribution (since Markowitz, 1952). On one hand, by means of experiments, psychologists and economists find out that investors display different biases in making their decisions: for example, they can over or under estimate probability (Kahneman and Tversky, 1972) and are strongly influenced by they way a problem is framed (Tversky and Kahneman, 1981). Based on this evidence, subjects can not be defined as perfectly rational.

On the other hand, the utility function considers also higher (central) moments of the return distribution. Scott and Horvath (1980) and Kane (1982) underline that higher order risk preferences are important determinants of subjects' behavior. Scott and Horvath (1980) prove that, starting from the standard assumptions of a utility function with positive first derivative (positive marginal utility) and negative second derivative (risk aversion), a rational subject will prefer higher values of the odd moments and lower values of the even moments of the return distribution. Formally

$$
(-1)^{n} u^{n}(x)<0 \quad \forall 0 \leq x \leq 1
$$

where $u^{n}$ is the $\mathrm{n}$-th derivative of the utility function. In the mean-variance standard framework only the positive first and the negative second derivative have been considered and labeled as nonsatiation and risk aversion, respectively. Behavioral finance refers to preference for positive third, negative fourth, and positive fifth derivatives as prudence (Kimball, 1990), temperance (Kimball, 1992), and edginess (Lajeri-Chaherli, 2004) respectively. For a larger review and a discussion on some terminological issues, see Colasante and Riccetti (2020).

After the paper by Eeckhoudt and Schlesinger (2006), in the last few years a fair number of experimental investigations have been performed on the idea of preference for higher moments of the return distribution (for a comprehensive review see Gollier et al., 2013, and Trautmann and van de Kuilen, 2018). For instance, Astebro et al. (2009), Deck and Schlesinger (2010, 2018), Ebert and Wiesen (2011, 2014), Maier and Ruger (2012), Noussair et al. (2014), Haering et al. (2017) and Baillon et al. (2018) find support for prudence. Even if Brünner et al. (2011) find a high degree of heterogeneity about preference for a higher third moment, to sum up, the evidence that the majority of people are prudent is robust. Regarding the role played by the fourth moment, Deck and Schlesinger (2010) find evidence for intemperance, while Maier and Ruger (2012), Noussair et al. (2014), and Deck and Schlesinger (2018) observe temperance. However, in general, results are weaker: it has been shown that the proportion of people making temperate choices is usually smaller than that making prudent ones (see, for example, Ebert and Wiesen, 2014; Heinrich and Mayrhofer, 2018; and Krieger and Mayrhofer, 2017). For a quick resume, see Appendix A1 of Haering et al. (2017). Investigations usually stop to the fourth moment, because behaviors at higher orders are often the same of making random choices. For instance, Deck and Schlesinger (2014) study also the fifth and sixth moments finding that behavior at these orders is only marginally different from making random choices. They affirm: "although we can theoretically consider risk preferences for any arbitrary order n, restricting any analyses within economic applications to only the first four orders seems a reasonable approximation. We attribute this phenomenon to the ever 
increasing complexity involved with deciphering higher degrees of risk increases".

A goal of this paper is to provide a measure for risk aversion able to include higher order risk preferences and to assess the relation between financial and non-financial risk attitude. In addition to the financial questions usually implemented to elicit risk preferences, we ask to a very large and heterogeneous population to answer to 20 additional questions related to personal features and risky behaviors in everyday life. The collection of such information allows us to build two synthetic measures for risk attitude: the "Financial all moments risk propensity score" and the "Non-financial risk propensity score". The former index, deeply analyzed in Colasante and Riccetti (2020), is based on the theoretical predictions provided by Scott and Horvath (1980) and it is computed on the answers on financial choices ${ }^{1}$. On the contrary, by looking at the non-financial decisions (e.g., smoking behavior, cheating to exams), we build the second index. To the best of our knowledge, the consistency between the inclination to financial and non-financial risks is a topic scarcely studied in economics, in particular if we include the analysis of preferences on higher moments of the return distribution. Dohmen et al. (2011) explain that in economics it is common to think of individuals as having an underlying risk preference that affects willingness to take risks in all contexts, but there is considerable controversy on this point in psychology.

Moreover, another goal of the current work is to provide an investigation to check whether risky decisions (in both financial and non-financial domains) are correlated with particular personal features. Therefore, our analysis is carried out by focusing on the answers to queries related to personal features and risky behaviors in everyday life non-financial decisions asked at the end of the questions on the risky lotteries. The questionnaire is reported in Appendix A. The data refers to the questionnaire proposed in Colasante and Riccetti (2020). That work investigates how subjects take into account the first four moments of the return distribution in making risky decisions. The questionnaire is short and built as simply as possible in order to reduce random choices. That analysis is useful for many reasons. First of all, results are collected from a very large and heterogeneous population (while previous studies on higher orders of the return distribution usually use smaller and less diversified samples); indeed, by using the powerful tool of Amazon Mechanical Turk, the sample includes people from different countries and with heterogeneous sociodemographic characteristics. The large and heterogeneous sample is useful to: (i) provide more general and unbiased results, (ii) analyse the different risk attitudes among geographical areas and demographic characteristics. In the current paper, data collected about both geographical and socio-demographic characteristics are deployed to investigate if people with different traits show homogeneous behavior in terms of risk aversion. Little evidence exists in the literature on this topic. Weber and Hsee (1998), Vieider et al. (2015a) and Vieider et al. (2015b) provide evidence of differences in risk attitudes across countries, and Haering et al. (2017) find that Chinese people are a little more risk prone compared to US and German people. However, the geographical difference is not the only relevant feature: for instance, Halek and Eisenhauer (2001) investigate the correlation between risk aversion and some demographic characteristics like age, employment and education, finding that such characteristics strongly influence risk aversion. Dohmen et al. (2017) and Schildberg-Hörisch (2018) also remark that risk aversion increases with age. Noussair et al. (2014) report some other very interesting results: for instance, older people are less risk averse,

\footnotetext{
${ }^{1}$ In Colasante and Riccetti (2020) a "Financial all moments risk aversion score" is built. Indeed, some authors, such as Deck and Schlesinger (2014) and Haering et al. (2017), try to describe the whole behavior of the agent. In particular, in the EU theory, the most common kind of agents empirically found presents "risk aversion" or " $m i x e d$ risk aversion", as defined by Caballe and Pomansky (1996), that is their utility function has derivatives that alternate their sign with the first derivative strictly positive, as in Scott and Horvath (1980). Given that this kind of definitions can cause confusion, as explained in Colasante and Riccetti (2020), we will use the term "all moments risk aversion" for a person with a preference for higher odd moments and lower even moments (that is, with a higher "Financial all moments risk aversion score").
} 
and people with high cognitive ability and high education are more prudent. Barsky et al. (1997) found that risk aversion over large stakes are correlated with financial decisions as well as with other risk-related behaviors, such as smoking and heavy drinking. Gender differences, contrary to the geographical ones, caught the interest of many scholar. The majority of results talks in favor of higher risk aversion for women (see, for instance, Eckel and Grossman, 2008; Croson and Gneezy, 2009; Ebert and Wiesen, 2014; Noussair et al., 2014; Filippin and Gioia, 2018). Moreover, Ebert and Wiesen (2014) find that, with marginal significance, women are also more prudent and temperate, and Noussair et al. (2014) find that females are more temperate, but they find no gender effect for prudence. Gender effect is also found outside financial domain: Byrnes et al. (1999) conduct a meta-analysis of 150 studies comparing risk-taking behaviors of men and women in a variety of domains (e.g. financial or health risks), and they find that men are more risk-taking, though the magnitude of the gender difference varied among different domains. Weber et al. (2002) also study gender differences in different domains (financial, health/safety, ethics, recreational, social), and find that women are more risk-averse in all domains except social risk. Moreover, they find an average correlation among the five analyzed domains scores of 0.44 , that is a significantly positive value, but far from 1, therefore, respondents' degree of risk taking is also domain-specific (even if they find that differences in risk taking are associated with differences in the perception of the activities' benefits and risk, rather than with differences in attitude towards perceived risk). We provide additional results based on analysis similar to those presented up to now.

The rest of the paper is structured as follows: Section 2 explains the experiment and the scores on financial and non-financial risk propensity built to perform the subsequent analyses. Section 3 presents some statistical analysis on the relations among the scores. Section 4 tries to unveil some of the features of the subjects that can influence the risk aversion in financial and non financial contexts. Section 5 reports the results on the correspondences among behaviors in financial and non-financial choices. Finally, Section 6 concludes.

\section{The experiment}

The experiment involves a large and heterogeneous sample. Indeed, it uses both a standard tool, i.e. the laboratory experiment, and the innovative Amazon Mechanical Turk (MTurk) tool. MTurk is an integrated participant compensation system able to obtain data inexpensively and rapidly. This tool is a particularly powerful method to obtain high-quality data, as explained by Goodman et al. (2013) and references therein. In particular, Goodman et al. (2013) reports that "researchers have verified that MTurk demographic responses are accurate (Rand, 2012), validated the psychometric properties of MTurk responses (Buhrmester et al., 2011), and replicated some of the classic findings in behavioral economics (Horton et al., 2011; Suri and Watts, 2011) and decision-making research (Paolacci et al., 2010)", and they find that "MTurk participants produce reliable results consistent with standard decision-making biases: they are present biased, risk-averse for gains, risk-seeking for losses, show delay/expedite asymmetries, and show the certainty effect-with almost no significant differences in effect sizes from other samples" ${ }^{2}$, therefore they "highly recommend MTurk to behavioral decision-making researchers because of its reliability, low cost, speed of data collection, and

\footnotetext{
${ }^{2}$ Both Paolacci et al. (2010) and Goodman et al. (2013) detect a slight difference in terms of risk aversion between MTurk and student samples. In particular, MTurk participants seem to be more risk averse compared to students. However, in our opinion, this difference may be (at least partially) attributed to age difference: MTurk participants are on average older than students, and attitude toward risk changes depending on age. In particular, the degree of risk aversion increases with age: elder people are less likely to take risk with respect to young people, as reported by many authors such as the already cited Dohmen et al. (2017) and Schildberg-Hörisch (2018), and as found by us in the current analysis.
} 
heterogeneity of participants". Moreover, our analysis does not present the problems that can be related to the use of MTurk. Indeed, researchers worry that MTurk workers do not pay sufficient attention to study materials and might cheat in answering questions with simple fact-checking (for instance on websites): we do not have these kind of problems, given that there are not materials to be studied and there are not "right" answers.

The sample is composed of 83 students from the University of Macerata (who performed a laboratory experiment) and 395 respondents from Amazon Mechanical Turk. The comparison between the two sub-samples shows that results are consistent despite different elicitation method and demographic composition. This is consistent with Goodman et al. (2013): they find that MTurk participants have attitudes about money similar to students' attitudes. For this reason we will present the analysis as if we had a unique sample composed of 478 subjects.

The questionnaire is short and simple, because when questions are too complex, a lot of agents tend to reply randomly: Deck and Schlesinger (2014) attribute the weak significance of the results on fifth and sixth order attitudes "to the ever increasing complexity involved with deciphering higher degrees of risk increases". Therefore, for instance, questions used in the current experiment regarding financial risk are binary choices and each choice presents a binary risk till the third moment analysis (indeed, as explained by Ebert, 2015, it is possible to provide an explicit reparametrization of binary risks in terms of their first three moments). Consequently, about half of the respondents take less than 7 minutes and the average time is about 10 minutes.

The questionnaire contains 11 choices regarding financial risk ${ }^{3}, 9$ questions on non-financial risks, 10 personal questions and 1 question on the self-assessment of the risk propensity. All the questions are reported in Appendix A. To avoid any bias due to the order of appearance, the order of the financial risk block queries is randomized, so that each subject answers the same questions but following a different order. Moreover, the experiments adds a consistency question, that is the age ten years ago, and a rationality score (for details, see Colasante and Riccetti, 2020); subsequently, two subjects who were both inconsistent and with a rationality score equal to zero, were deleted assuming that all answers were randomly chosen. Two further respondents with missing answers were deleted, so that, the final dataset includes 478 subjects, as already said. Results are robust to various refinements (such as a higher minimum value of the rationality score), therefore we decide to analyze the (almost) whole sample.

The 11 questions on non-financial risks include 7 questions on second moment (or risk aversion), 2 questions on third moment (or prudence), 2 questions on fourth moment (or temperance).

Now we connect the risk aversion on financial choices with the risk aversion on other kinds of risks involving health/safety and illegal behavior. Following the methodology used by Weber et al. (2002), respondents evaluate their likelihood of engaging in some risk behaviors on a five-point rating scale ranging from 1 (very unlikely) to 5 (very likely). In particular, the questionnaire asks people if they are prone (from 1 to 5 ) to perform the following activities:

- cheating in an exam,

- evading tax,

- shoplifting a small item (e.g. a pen),

- smoking,

\footnotetext{
${ }^{3}$ In reality, the questionnaire reported in Colasante and Riccetti (2020) contains 14 choices regarding financial risk, but 3 can not be applied to the current analysis: Question 0 on the first moment does not present a really risky choice, while Questions 8 and 10 (of that study) are excluded because they contain a "struggle" between different moments, that can take risk averse people to choose both alternatives.
} 
- periodically engaging in a dangerous sport,

- exposing to the sun without using sunscreen,

- going on a vacation in third-world country without prearranged travel and hotel accommodation,

- driving the car without fastening seat-belt,

- regularly eating high cholesterol foods.

In order to check the consistency between inclination to financial and to non-financial risks in a simple way, we compute for every subject both a "Financial all moments risk propensity score" and a "Non-financial risk propensity score". Moreover, we also divide the latter score in two sub-scores called "Legality" and "Health", composed of the first three and the last six questions respectively. The way in which both scores are computed will be explained in the next subsections.

Finally, we also compare the two scores with the "Overall risk propensity self-assessment" question: How do you see yourself: are you in general a person who takes risk or do you try to evade risk? Please self-grade your choice between 0 (I don't take risk at all) to 10 (I love to take risk).

\subsection{Financial all moments risk propensity score}

As explained in Section 1, Colasante and Riccetti (2020) use the questions on financial risk in order to build a "Financial all moments risk aversion score" based on Scott and Horvath's (1980) theoretical prediction. This is exactly the same as counting the number of risk averse or risk loving choices performed by Deck and Schlesinger (2014) and Haering et al. (2017) to assess the presence of the so-called "mixed risk averse" behavioral pattern.

In particular, three scores on second, third and fourth moments are built and the "Financial all moments risk aversion score" (mixed risk aversion) is computed as the sum of the three scores.

In this paper we build a risk propensity (rather than a risk aversion) score based on non-financial questions. Therefore, for the sake of comparability (low values for stronger risk aversion and high values for stronger risk propensity), we flip the financial risk aversion score by building the "Financial all moments risk propensity score" (in practice, if the aversion score is 11, the propensity score is 0 and vice versa).

The propensity score for the second moment is computed in the following way: for each question a value 1 is assigned to those subjects who choose the option with the larger second moment and 0 otherwise. Since we propose 7 questions, the second moment score ranges from 0 to 7 .

In a similar way, the score for the third moment is computed by assigning 1 point to subjects who choose the option with the smaller third moment in Question 8 and 9 and zero otherwise. In this case, since we are taking into account only two questions, the score ranges from 0 to 2 .

Lastly, for the fourth moment score, respondents that choose the option with larger fourth moment in Questions 10 and 11 obtain one point and zero otherwise, with a final score that ranges from 0 to 2 .

As already said, the total "Financial all moments risk propensity score" is the sum of the three scores just described and, therefore, it ranges from 0 (very risk averse subject) to 11 (very risk prone subject). Table 1 shows, for each question, the choice that a risk prone subject would have made. Subjects who follow this path of answers, obtain 11 points for this score. Results show a tendency of respondents to be risk averse, with a preference for a lower second moment and a higher third moment (and no statistically significant preference for a higher or lower fourth moment).

Panel (a) of Table 2 shows the distribution of subjects by total "Financial all moments risk propensity score", including the related percentage and cumulative percentage values. We can 
Table 1: "Financial all moments risk propensity score": options that obtain 1 point each.

\begin{tabular}{|l|c|c|c|c|c|c|c|c|c|c|c|}
\hline Question & 1 & 2 & 3 & 4 & 5 & 6 & 7 & 8 & 9 & 10 & 11 \\
\hline Risky option & A & B & A & A & A & A & B & A & A & A & A \\
\hline
\end{tabular}

roughly divide the distribution in four buckets, reported in Table 4: very risk averse persons (score 0-2) are almost $15 \%$ of the sample; moderately risk averse subjects (score 3-5) are half of the sample; moderately risk prone subjects (score 6-8) are almost a third of the sample, and risk prone people (scores 9-11) are very few (less than $4 \%$ and none obtains 11). However, only two subjects are fully risk averse, while almost all respondents (96\%), obtains intermediate values from 1 to 8 , showing they enjoy various levels of risk propensity ${ }^{4}$. The large heterogeneity in behaviors is a recurrent feature, consistently with the findings of von Gaudecker et al. (2011). Moreover, these authors also state that "while many people exhibit consistent choice patterns, some have very high error propensities", often associated with the propensity to choose randomly rather than on the basis of preferences.

For further details on the many other results found and, in particular, on the three scores on second, third and fourth moments and their correlations, see Colasante and Riccetti (2020).

Table 2: Marginal distributions of (a) total "Financial all moments risk propensity score", (b) "Overall risk propensity self-assessment" (from 0, very risk averse, to 10 or 11, very risk prone).

(a) Financial

\begin{tabular}{|l|c|c|c|}
\hline Score & Freq. & Percent & Cum. \\
\hline 0 & 2 & 0.42 & 0.42 \\
\hline 1 & 22 & 4.60 & 5.02 \\
\hline 2 & 45 & 9.41 & 14.43 \\
\hline 3 & 79 & 16.53 & 30.96 \\
\hline 4 & 83 & 17.36 & 48.32 \\
\hline 5 & 76 & 15.90 & 64.22 \\
\hline 6 & 71 & 14.85 & 79.07 \\
\hline 7 & 52 & 10.88 & 89.95 \\
\hline 8 & 31 & 6.49 & 96.44 \\
\hline 9 & 15 & 3.14 & 99.58 \\
\hline 10 & 2 & 0.42 & 100.00 \\
\hline 11 & 0 & 0.00 & 100.00 \\
\hline
\end{tabular}

(b) Overall self-assessment

\begin{tabular}{|l|c|c|c|}
\hline Score & Freq. & Perc. & Cum. \\
\hline 0 & 12 & 2.51 & 2.51 \\
\hline 1 & 26 & 5.44 & 7.95 \\
\hline 2 & 42 & 8.79 & 16.74 \\
\hline 3 & 50 & 10.46 & 27.20 \\
\hline 4 & 60 & 12.55 & 39.75 \\
\hline 5 & 76 & 15.90 & 55.65 \\
\hline 6 & 50 & 10.46 & 66.11 \\
\hline 7 & 70 & 14.64 & 80.75 \\
\hline 8 & 61 & 12.76 & 93.51 \\
\hline 9 & 23 & 4.81 & 98.33 \\
\hline 10 & 8 & 1.67 & 100.00 \\
\hline
\end{tabular}

\footnotetext{
${ }^{4}$ As explained by Deck and Schlesinger (2014) making even one risk-loving decision might disqualify an individual from being labeled as "risk averse". Therefore, following many authors, such as Wilcox (2008), Maier and Ruger (2012), and Deck and Schlesinger (2014), a stochastic type of labeling is adopted: we refer to someone who obtains at most a fixed maximum value of the "Financial all moments risk propensity score" as being "financially risk averse". This approach is performed also in social psychology. For instance, in the theory of planned behavior by Ajzen (1991), attitudes and subjective norms about a behavior influence behavioral intentions which, in turn, determine the likelihood of the behavior occurring.
} 


\section{2 "Non-financial risk propensity score"}

In order to check the consistency between inclination to financial and to non-financial risks in a simple way, we compute a "Non-financial risk propensity score". As for the "Financial all moments risk propensity score", we try to be as simple and as less arbitrary as possible. Therefore, for every subject, we simply sum the score given to each question. Given that we ask 9 non-financial questions, at the end, every person has a "Non-financial risk propensity score" ranging from 9 (very risk averse) to 45 (very risk prone). Moreover, we also divide this score in two sub-scores called "Legality" and "Health", composed of the first three and the last six questions respectively.

Table 3 reports the results about these scores: the majority of subjects tend to self grade as quite risk averse. Focusing on the total score (Panel (a) of Table 3), to simplify the analysis, we build "Non-financial risk propensity buckets" dividing the distribution in four buckets as done for the financial score: the "Non-financial risk propensity bucket" is equal to 4 for subjects with "Non-financial risk propensity score" between 36 and 45, is equal to 3 when the propensity score is between 27 and 35, equal to 2 when the propensity score is between 18 and 26, and equal to 1 otherwise. We find that $39 \%$ of subjects is very risk averse obtaining a score between 9 and 17 (bucket 1), and $43 \%$ is quite risk averse with a score between 18 and 26 (bucket 2), while $14 \%$ appears quite risk prone obtaining a score between 27 and 35 (bucket 3), and only $4 \%$ is very risk prone with a score between 36 and 45 (even if this bucket has a range of 10 scores, therefore it is larger than the others that have a range including 9 scores only). The number of respondents for each buckets is reported in the last line of Table 5 .

\section{A comparison among financial score, non-financial scores, and "Overall risk propensity self-assessment"}

Comparing these results with the results obtained for the "Financial all moments risk propensity score", we find that respondents show a stronger propensity to risk in the financial domain, indeed less than the $15 \%$ of respondents are in the first bucket (score 0-2), while the $39 \%$ of subjects are very risk averse in the non-financial domain (score 9-17). This difference is very pronounced with both "Health" and "Legality" indexes, whose buckets are built as for the buckets on "Non-financial risk propensity score" (that is with a larger range for bucket 4), and are reported in Table 4. However, the "Legality" index reports an even stronger risk aversion: almost the $63 \%$ of subjects belong to the bucket of the very risk averse persons (score 3-5 for this index).

The financial and the non-financial scores present a statistically significant correlation equal to $26 \%$, as reported in Table 6 . In order to display this correlation, we put in Table 5 the joint distribution of "Financial all moments risk propensity score" and "Non-financial risk propensity buckets". Table 5 confirms the found correlation: for instance respondents that obtain the lowest value $(0)$ in the "Financial all moments risk propensity score" are in the bucket of the very risk averse persons (bucket 1) for the non-financial risks too. However, there are subjects with quite different results in the two scores: for instance 7 subjects obtain 9 in the "Financial all moments risk propensity score", that is they are quite risk prone, but they are in the first "Non-financial risk propensity bucket", that is they are very risk averse in non-financial domains. These cases can be interpreted (at least) in four very different ways:

- respondents reply randomly to the questions;

- respondents are not fully able to self assess their risk aversion; 
Table 3: Marginal distributions of (a) total "Non-financial risk propensity score", (b) "Non-financial risk propensity score" - Health, and (c) "Overall risk propensity self-assessment" - Legality.

(a) Total non-financial

\begin{tabular}{|c|c|c|c|}
\hline Score & Freq. & Percent & Cum. \\
\hline 9 & 16 & 3.35 & 3.35 \\
\hline 10 & 7 & 1.46 & 4.81 \\
\hline 11 & 15 & 3.14 & 7.95 \\
\hline 12 & 20 & 4.18 & 12.13 \\
\hline 13 & 22 & 4.60 & 16.74 \\
\hline 14 & 28 & 5.86 & 22.59 \\
\hline 15 & 23 & 4.81 & 27.41 \\
\hline 16 & 33 & 6.90 & 34.31 \\
\hline 17 & 23 & 4.81 & 39.12 \\
\hline 18 & 35 & 7.32 & 46.44 \\
\hline 19 & 28 & 5.86 & 52.30 \\
\hline 20 & 29 & 6.07 & 58.37 \\
\hline 21 & 38 & 7.95 & 66.32 \\
\hline 22 & 16 & 3.35 & 69.67 \\
\hline 23 & 17 & 3.56 & 73.22 \\
\hline 24 & 14 & 2.93 & 76.15 \\
\hline 25 & 14 & 2.93 & 79.08 \\
\hline 26 & 14 & 2.93 & 82.01 \\
\hline 27 & 16 & 3.35 & 85.36 \\
\hline 28 & 10 & 2.09 & 87.45 \\
\hline 29 & 5 & 1.05 & 88.49 \\
\hline 30 & 7 & 1.46 & 89.96 \\
\hline 31 & 7 & 1.46 & 91.42 \\
\hline 32 & 6 & 1.26 & 92.68 \\
\hline 33 & 7 & 1.46 & 94.14 \\
\hline 34 & 8 & 1.67 & 95.82 \\
\hline 35 & 1 & 0.21 & 96.03 \\
\hline 36 & 7 & 1.46 & 97.49 \\
\hline 37 & 2 & 0.42 & 97.91 \\
\hline 38 & 3 & 0.63 & 98.54 \\
\hline 39 & 1 & 0.21 & 98.74 \\
\hline 40 & 2 & 0.42 & 99.16 \\
\hline 41 & 1 & 0.21 & 99.37 \\
\hline 42 & 0 & 0.00 & 99.37 \\
\hline 43 & 1 & 0.21 & 99.58 \\
\hline 44 & 0 & 0.00 & 99.58 \\
\hline 45 & 2 & 0.42 & 100.00 \\
\hline
\end{tabular}

(b) Health

\begin{tabular}{|c|c|c|c|c|c|c|c|}
\hline Health & Freq. & Percent & Cum. & & & & \\
\hline 6 & 17 & 3.56 & 3.56 & & & & \\
\hline 7 & 13 & 2.72 & 6.28 & & & & \\
\hline 8 & 16 & 3.35 & 9.62 & & & & \\
\hline 9 & 34 & 7.11 & 16.74 & & & & \\
\hline 10 & 27 & 5.65 & 22.38 & & & & \\
\hline 11 & 35 & 7.32 & 29.71 & Legality & Freq. & Percent & Cum. \\
\hline 12 & 31 & 6.49 & 36.19 & 3 & 176 & 36.82 & 36.82 \\
\hline 13 & 32 & 6.69 & 42.89 & 4 & 60 & 12.55 & 49.37 \\
\hline 14 & 45 & 9.41 & 52.30 & 5 & 64 & 13.39 & 62.76 \\
\hline 15 & 35 & 7.32 & 59.62 & 6 & 45 & 9.41 & 72.18 \\
\hline 16 & 30 & 6.28 & 65.90 & 7 & 35 & 7.32 & 79.50 \\
\hline 17 & 22 & 4.60 & 70.50 & 8 & 19 & 3.97 & 83.47 \\
\hline 18 & 32 & 6.69 & 77.20 & 9 & 19 & 3.97 & 87.45 \\
\hline 19 & 21 & 4.39 & 81.59 & 10 & 20 & 4.18 & 91.63 \\
\hline 20 & 22 & 4.60 & 86.19 & 11 & 17 & 3.56 & 95.19 \\
\hline 21 & 19 & 3.97 & 90.17 & 12 & 9 & 1.88 & 97.07 \\
\hline 22 & 15 & 3.14 & 93.31 & 13 & 4 & 0.84 & 97.91 \\
\hline 23 & 9 & 1.88 & 95.19 & 14 & 7 & 1.46 & 99.37 \\
\hline 24 & 7 & 1.46 & 96.65 & 15 & 3 & 0.63 & 100.00 \\
\hline
\end{tabular}

Table 4: Risk propensity buckets distribution (from 1, risk averse bucket, to 4, risk prone bucket) in financial and non-financial domains.

\begin{tabular}{|l|c|c|c|c|}
\hline Risk propensity & 1 & 2 & 3 & 4 \\
\hline Financial & $14,44 \%$ & $49,79 \%$ & $32,22 \%$ & $3,56 \%$ \\
\hline Health & $29,71 \%$ & $40,79 \%$ & $24,69 \%$ & $4,81 \%$ \\
\hline Legality & $62,76 \%$ & $20,71 \%$ & $11,72 \%$ & $4,81 \%$ \\
\hline
\end{tabular}


Table 5: Joint distribution of subjects by Financial (from 11 to 0 , in rows) and Non-financial (from 4 to 1 , in columns) risk propensities.

\begin{tabular}{|l|c|c|c|c|c|}
\hline Risk Propensity & 4 & 3 & 2 & 1 & Total \\
\hline 11 & 0 & 0 & 0 & 0 & 0 \\
\hline 10 & 1 & 1 & 0 & 0 & 2 \\
\hline 9 & 0 & 2 & 6 & 7 & 15 \\
\hline 8 & 6 & 6 & 6 & 13 & 31 \\
\hline 7 & 5 & 14 & 19 & 14 & 52 \\
\hline 6 & 3 & 13 & 30 & 25 & 71 \\
\hline 5 & 2 & 14 & 34 & 26 & 76 \\
\hline 4 & 2 & 10 & 42 & 29 & 83 \\
\hline 3 & 0 & 5 & 34 & 40 & 79 \\
\hline 2 & 0 & 1 & 21 & 23 & 45 \\
\hline 1 & 0 & 1 & 13 & 8 & 22 \\
\hline 0 & 0 & 0 & 0 & 2 & 2 \\
\hline Total & 19 & 67 & 205 & 187 & 478 \\
\hline
\end{tabular}

- respondents could lie when answering questions such as on the propensity to evade taxes, and this explanation could be supported by the huge level of risk aversion found in the "Legality" index;

- respondents really present different behaviors for financial and non-financial risks, with usually a larger risk aversion in domains like health and legality compared to the financial domain. This could be similar to the result of Deck and Schlesinger (2018), who find that behavior differs between monetary and non-monetary outcomes, and of Weber et al. (2002), who find different average results for financial, health/safety, and ethics domains (even if they perform more than one study, and in one case respondents seem to be more prone towards financial risks, while in another case respondents seem to be more prone towards health/safety risks).

As already said, to have some further insights about the ability of respondents to self assess their risk aversion, we also ask them the "Overall risk propensity self-assessment" question reported in Section 2. The distribution of choices is reported in Panel (b) of Table 2. In this case, people allocate themselves in quite a symmetric way between opposite values of risk propensity, tending to overrate their overall risk propensity compared to the other scores (even if it is always difficult to judge upon ordinal values). However, the correlations between this overall self-assessment and both the "Financial all moments risk propensity score" and the "Non-financial risk propensity score" is above $40 \%$ as reported in Table 6. This result is in line with Dohmen et al. (2011) who state that the "question about risk-taking in general generates the best all-around predictor of risky behavior". Therefore, on the one hand, we can support the statements that respondents sometimes reply randomly or are probably not fully able to self assess their risk aversion (different distributions among various scores and correlations far from 1). But, on the other hand, these correlations are quite high and they are both higher than the correlation between financial and non-financial scores equal to $26 \%$, suggesting that respondents really present different behaviors for financial and nonfinancial risks. Therefore, we think that all the four interpretations could be jointly at work.

We also perform a deeper analysis on the relations between the "Overall risk propensity selfassessment" and the behaviors investigated in our questionnaire. In practice, we estimate an ordered 
Table 6: Correlations among total "Financial all moments risk propensity score", "Non-financial risk propensity score" (divided in Panel B in Health and Legality), and "Overall risk propensity self-assessment".

\begin{tabular}{|c|c|c|c|c|}
\hline Panel A & Financial & \multicolumn{2}{|c|}{ Non-financial } & \multirow[t]{2}{*}{ Overall } \\
\hline Financial & 1 & & & \\
\hline Non-financi & 0.26 & & 1 & \\
\hline Overall & 0.41 & & 0.42 & 1 \\
\hline Panel B & Financial & Health & Legality & Overall \\
\hline Financial & 1 & & & \\
\hline Health & 0.20 & 1 & & \\
\hline Legality & 0.29 & 0.58 & 1 & \\
\hline Overall & 0.41 & 0.35 & 0.42 & 1 \\
\hline
\end{tabular}

logit on "Overall risk propensity self-assessment" using as independent variables the answers on risk propensity on non-financial activities, used to compute the total "Non-financial risk propensity score", the "Financial risk propensity score", and the socio-demographic characteristics of the respondents (tables with results are available from the authors upon request). Besides the sociodemographic characteristics that will be analyzed in Section 4, the results show that people tend to rate themselves as more risk prone (higher value of the "Overall risk propensity self-assessment") when they also affirm to be more prone to evading tax, to engaging in a dangerous sport and to going on holiday in a third-world country without prearranged travel. The total "Financial all moments risk propensity score" is very statistically significant, confirming the correspondence between self-evaluation and financial behavior. Therefore, when people think about their overall risk propensity, they are really including various domains (activities that could be risky for their health, such as dangerous sports, ethical risks, such as propensity to evade tax, and financial risk).

To conclude, our results (even if found correlations are a bit lower) are consistent with the findings of previous papers such as Weber et al. (2002) and Dohmen et al. (2011). In particular, Dohmen et al. (2011) explain that risk attitudes are correlated, but not perfectly correlated, across contexts. Indeed, they state: "This suggests the presence of a common underlying risk trait, but also points to some value-added from asking context-specific questions".

\section{Financial and non-financial risk aversion determinants}

In this section, we try to understand the possible determinants of risk aversion. To perform this task, Colasante and Riccetti (2020) conduct an ordered logit analysis for the "Financial all moments risk aversion score". In this paper, after summarizing the results of that analysis, we repeat the same analysis using as dependent variables the total "Non-financial risk propensity score", and the "Overall risk propensity self-assessment". Therefore, we present the results of the three ordered logit analysis for the three scores on the following variables: age, gender, marital status, home (owned, rented...), labor status, social class, family income range, number of vacations in the last year (as a proxy for the consumption propensity or as an alternative proxy for the level of income), level of education, and country (we build a dummy only for areas with at least 10 observations, that is USA, India, Italy, Canada and Europe other than Italy; however, in the sample there are persons coming from Africa, Asia other than India, Latin America, and Australia). For a detailed description of the questions and of the possible choices, see Appendix A. 
We perform various specifications of the ordered logit model with different explanatory variables, also using the stepwise selection procedure ${ }^{5}$. We report some tables presenting the most relevant estimation results, and we summarize the main and most robust results ${ }^{6}$.

The main findings of Colasante and Riccetti (2020) about the determinants of the "Financial all moments risk aversion score", may be summarized as follows:

- people prefer lower second moments (are risk averse) when they are older and/or they live in Europe, while they tend to be more risk prone (even if this result is not present in all the estimates done with different sets of explanatory variables) when they are employees and/or they live in India.

- Respondents prefer higher third moments (are prudent) if they are older and/or women. Moreover, Italians seem to be more prudent, even if this dummy is almost overlapping with the dummy "student".

- Subjects prefer lower fourth moments (temperance) if they live in Europe (both Italy and Europe dummies are significant). Moreover, even if these results are not present in all the estimates, they tend to prefer lower fourth moments if they live in the USA, and higher fourth moments when they are single or employees.

- Therefore some determinants (such as age) influence different moments, while other determinants seem to be specific of the risk aversion of a particular moment.

- The total score, composed by the three scores and mainly related to the second moment one, reflects the previous results. In particular, people present a higher risk aversion if they are older or live in "Western countries" (dummies Europe, Italy, Canada and USA).

Using the ordered logit to find the determinants of the total "Non-financial risk propensity score", we discover that people living in USA and/or having a higher educational level and/or being older and/or being female state to be less prone to carry out illegal or dangerous activities. Moreover, even if with a lower p-value (between $5 \%$ and 10\%) or being statistically significant only in some specifications, we find that students are more risk averse, singles are more risk prone and those who go more often on vacation (as a proxy of propensity to consume and proxy of income, even if the variable income is not statically significant) are more risk prone in non-financial activities. These results are reported in Table 7. Some of these results were expected and confirm usual findings of economic and psychological literature; for instance, Dohmen et al. (2011) find that women, older and married persons are more risk averse also in non financial activities.

Finally, we try to understand the determinants of the "Overall risk propensity self-assessment". In this case many variables result statistically significant, as reported in Table 8. In particular, people feel more risk averse when they:

- are older;

- live in "Western countries" (dummies Europe, Italy, Canada and USA, with a stronger risk aversion for the North America dummies, that is Canada and USA);

- are women;

\footnotetext{
${ }^{5}$ The stepwise selection procedures consists of iteratively removing the explanatory variable with the highest pvalue above a certain threshold (we fix 10\%) and adding the variable with the lowest p-value below a certain threshold (we fix 5\%).

${ }^{6}$ However, all regressions are available from the authors upon request.
} 
Table 7: Results of the ordered logit estimation. The dependent variable is the "Non-financial risk propensity score".

\begin{tabular}{lcc}
\hline \hline Non-financial risk propensity score & Coefficient & p-value \\
\hline & & \\
Age & -0.017 & $(0.054)$ \\
Education & -0.368 & $(0.000)$ \\
Male & 0.332 & $(0.053)$ \\
Vacation Frequency & 0.182 & $(0.039)$ \\
Single & 0.340 & $(0.064)$ \\
Own House & -0.774 & $(0.007)$ \\
Rent House & -0.610 & $(0.041)$ \\
USA & -0.803 & $(0.000)$ \\
Student & -0.753 & $(0.002)$ \\
\hline & & \\
N & 448 & \\
LR & $74,70^{* * *}$ & \\
Pseudo R2 & 0.0256 & \\
\hline
\end{tabular}

- belong to a lower social class. This result is strengthened by the variable on the frequency of vacations (people who go on holiday less frequently, who probably belong to a lower social class, tend to be more risk averse), but weakened by the fact that the income class variable does not result statistically significant; perhaps, compared to the income class, the social class is more related to the perception of ourselves compared to our neighbors and can influence more directly the risk propensity self-assessment;

- are unemployed (or students/retired/fulfilling domestic tasks). Employees feel more risk prone and self-employed respondents even more.

Again, some results were expected and confirm the findings of other papers. For instance, Dohmen et al. (2011) find that older persons, retired persons, and women are in general more risk averse, while self-employee are more risk prone.

Summarizing the results, age is the most important and robust determinant of risk aversion: older people are more risk averse. Another persistent result is that people living in "Western countries" are more risk averse, with European subjects more risk averse in financial choices and North American subjects more risk averse in non-financial activities. To a lesser extent, other features seem to affect the risk aversion: students of economics and women seem to be more risk averse, while single people and employees appear more risk prone. Unexpectedly, selfemployed persons appear less risk prone in financial choices, even if they overall evaluate themselves more risk prone. Another partially unexpected result is that to belong to a lower social class or to be unemployed seems to be associated with a stronger risk aversion in non-financial activities but not in financial choices, while we think that these features should also affect financial choices. 
Table 8: Results of the ordered logit estimation. The dependent variable is the "Overall risk propensity self-assessment".

\begin{tabular}{lcc}
\hline \hline Overall risk propensity self-assessment & Coef. & p-value \\
\hline & & \\
Age & -0.033 & $(0.000)$ \\
Male & 0.598 & $(0.001)$ \\
Vacation Frequency & 0.243 & $(0.008)$ \\
Italy & -0.847 & $(0.010)$ \\
Europe & -0.898 & $(0.011)$ \\
USA & -1.117 & $(0.000)$ \\
Canada & -2.03 & $(0.000)$ \\
Social Class & 0.234 & $(0.044)$ \\
Self Employed & 0.991 & $(0.001)$ \\
Employee & 0.582 & $(0.015)$ \\
\hline & & \\
N & 448 & \\
LR & $122,70^{* * *}$ & \\
Pseudo R2 & 0.06 & \\
\hline
\end{tabular}

\section{Correspondences among behaviors in financial and non- financial choices}

In this section, we try to understand the correspondences among behaviors in financial and nonfinancial choices. Now, we do not search for the exogenous variables (such as age or gender) that can determine the risk propensity, but we simply analyse the relations among behaviors in financial and non-financial choices. We emphasize that any relationship found in the current analysis should not be interpreted with respect to causality.

To perform this task, we repeat the ordered logit analysis previously performed adding the variables used to build the "Non-financial risk propensity score". In practice, we estimate an ordered logit on total "Financial all moments risk propensity score" using all variables: both socio-demographic characteristics and the answers on risk propensity on non-financial activities used to compute the total "Non-financial risk propensity score".

Results are reported in Table 9. We find that the "Financial all moments risk propensity score" is related to the age of the respondent (inversely) and to the geographical location (people living in "Western countries", and in particular in Europe, are more risk averse). In addition, in some specifications, we observe that the financial risk propensity is positively related to risk propensity for "illegal" activities, in particular to shoplifting and cheating at exams. Moreover, even if with a p-value between $5 \%$ and $10 \%$ and only in some specifications, financial risk propensity is positively related to vacation in a third-world country without prearranged travel and negatively related to eating high cholesterol foods, perhaps because this activity is not considered dangerous.

We further check the robustness of our results by adding the "Overall risk propensity selfassessment" among the explanatory variables. Results are presented in Table 10. We find that this variable is very statistically significant, confirming that people are quite able to self-evaluate themselves. Moreover, this specification also confirms that financial risk aversion is positively related to age, to living in Europe, and to risk aversion to shoplifting.

Therefore, compared to the results already highlighted in the previous section, we can add 
that the activities that are more related to financial risk propensity are to shoplift, and to cheat at exams. Consequently, we can suppose that the propensity to perform illegal activities could be a good indicator of financial risk propensity and vice versa. However, an unexpected result concerns the propensity to evade tax: in our opinion (following authors, such as Allingham and Sandmo, 1972, who associate a higher financial risk aversion to a higher tax compliance), it should be related to financial risks, while it results statistically significant in the regression on the overall risk assessment and not in the regression on the financial risk score.

Table 9: Results of the ordered logit estimation. The dependent variable is the "Financial all moments risk propensity score".

\begin{tabular}{lcc}
\hline \hline Financial all moments risk propensity score & Coef. & p-value \\
\hline & & \\
Age & -0.038 & $(0.000)$ \\
Junk Food & -0.121 & $(0.071)$ \\
Cheating Exam & 0.186 & $(0.040)$ \\
Italy & -1.251 & $(0.000)$ \\
Europe & -1.277 & $(0.000)$ \\
USA & -0.491 & $(0.026)$ \\
Canada & -1.110 & $(0.028)$ \\
Shoplifting & 0.185 & $(0.015)$ \\
Third world trip & 0.149 & $(0.001)$ \\
\hline & & \\
N & 448 & \\
LR & $98,83^{* * *}$ & \\
Pseudo R2 & 0.05 & \\
\hline
\end{tabular}

Table 10: Results of the ordered logit estimation. The dependent variable is the "Financial all moments risk propensity score".

\begin{tabular}{lcc}
\hline \hline Financial all moments risk propensity score & Coef. & p-value \\
\hline Age & -0.032 & $(0.000)$ \\
Shoplifting & 0.209 & $(0.006)$ \\
Overall risk propensity self-assessment & 0.314 & $(0.000)$ \\
Italy & -0.491 & $(0.071)$ \\
Europe & -0.976 & $(0.003)$ \\
Income & -0.153 & $(0.056)$ \\
Employee & 0.347 & $(0.058)$ \\
\hline & & \\
N & 448 & \\
LR & $145,26^{* * *}$ & \\
Pseudo R2 & 0.08 & \\
\hline
\end{tabular}




\section{Conclusions}

The aim of this paper is twofold. Firstly, we investigate whether the personal features of the subjects can influence the risk attitude in financial and non-financial contexts. Secondly, we try to understand the correspondences among some behaviors in financial and non-financial choices.

Our contribution is strictly related to the analysis performed by Colasante and Riccetti (2020). That work investigates how subjects take into account the first four moments of the return distribution in making risky decisions. Indeed, higher order risk preferences are important determinants of financial choices done under uncertainty. For instance, there is a strong literature evidence on prudence: the majority of people prefers a return distribution with a higher third moment. Data is collected by a questionnaire built as simply as possible in order to reduce random choices. That analysis is useful because results are collected from a very large and heterogeneous population, and because it builds a "Financial all moments risk aversion score" based on Scott and Horvath (1980) theoretical prediction on preferences on the various moments of the return distribution for a rational risk averse subject. The current work provides an additional investigation to check whether risky decisions in financial and non-financial contexts are correlated and if they are both correlated to particular personal features. Indeed, Dohmen et al. (2011) explain that in economics it is common to think of individuals as having an underlying risk preference that affects willingness to take risks in all contexts, but there is considerable controversy on this point in psychology. To the best of our knowledge, the consistency between the inclination to financial risks, including an evaluation of the behavior towards higher moments of the return distribution, and non-financial risks is a topic scarcely studied in economics.

To perform the explained analyses, we build, beside the score on financial risk propensity/aversion, an additional score on non-financial risk propensity.

Among the possible determinants of risk propensity, we find that age and geographical location significantly affect risk propensity both in financial and non-financial domains. Moreover, in the financial context, there are some other determinants, such as gender, that seem to influence the risk aversion related to a particular moment only. In non-financial domains, we find some other personal features as determinants of risk propensity: students and women are more risk averse, while singles and employees appear more risk prone. Unexpectedly, self-employed persons appear less risk prone in financial choices, even if they overall evaluate themselves more risk prone. Another partially unexpected result is that to belong to a lower social class or to be unemployed seems to be associated with a stronger risk aversion in non-financial activities but not in financial choices, while we think that these features should also affect financial choices.

The analysis of the relationship between risk attitudes in financial and non-financial contexts, shows that to shoplift and to cheat at exams are related to financial risk propensity. Consequently, we can suppose that the propensity to perform illegal activities could be a good indicator of financial risk propensity and vice versa. Moreover, risk attitudes in financial and non-financial contexts are correlated, but correlation is far from 1, with a larger risk aversion in non-financial contexts. Our results are consistent with the findings of previous papers such as Weber et al. (2002) and Dohmen et al. (2011), showing that risk attitudes are correlated, but not perfectly correlated, across contexts. Therefore, there is a common underlying risk trait, but the context is also relevant and, consistently, overall risk aversion self assessment can be different to financial risk aversion evaluation because risky decisions do not solely concern the financial context. 


\section{References}

AJZen, I. (1991), "The theory of planned behavior", Organizational Behavior and Human Decision Processes, 50, pp. 179-211.

Allingham, M. And A. Sandmo (1972), "Income tax evasion: a theoretical analysis", Journal of Public Economics, 1(3-4), pp. 323-338.

Astebro, T., J. Mata and L. Santos-Pinto (2009), "Preference for skew in lotteries: Evidence from the laboratory", Paris, France: HEC Paris.

Baillon, A., H. Schlesinger and G. van de Kuilen (2018), "Measuring higher order ambiguity preferences", Experimental economics, 21(2), pp. 233-256.

Barsky, R., F. Juster, M. Kimball and M. Shapiro (1997), "Preference parameters and behavioral heterogeneity: An experimental approach in the health and retirement study", The Quarterly Journal of Economics, 112(2), pp. 537-579.

Brünner, T., R. LevínskỲ AND J. QIU (2011), "Preferences for skewness: evidence from a binary choice experiment", The European Journal of Finance, 17(7), pp. 525-538.

Buhrmester, M., T. Kwang and S. Gosling (2011), "Amazon's Mechanical Turk: A new source of inexpensive, yet high-quality, data?", Perspectives on psychological science, 6(1), pp. $3-5$.

Byrnes, J., D. Miller and W. Schafer (1999), "Gender differences in risk taking: a metaanalysis", Psychological Bulletin, 125, pp. 367-383.

Caballe, J. And A. Pomansky (1996), "Mixed risk aversion", Journal of Economic Theory, 71(2), pp. $485-513$.

Colasante, A. And L. Riccetti (2020), "Risk aversion, prudence and temperance: it is a matter of gap between moments", Journal of Behavioral and Experimental Finance, X(X), pp. X-XX.

Croson, R. and U. Gneezy (2009), "Gender differences in preferences", Journal of Economic literature, 47(2), pp. 448-74.

Deck, C. And H. Schlesinger (2010), "Exploring higher order risk effects", Review of Economic Studies, 77(4), pp. 1403-1420.

Deck, C. And H. Schlesinger (2014), "Consistency of higher order risk preferences", Econometrica, 82(5), pp. 1913-1943.

Deck, C. And H. Schlesinger (2018), "On the robustness of higher order risk preferences", Journal of Risk and Insurance, 85(2), pp. 313-333.

Dohmen, T., A. Falk, B. H. Golsteyn, D. Huffman, U. Sunde et al. (2017), "Risk Attitudes Across The Life Course", Economic Journal, 127(605), pp. 95-116.

Dohmen, T., A. Falk, D. Huffman, U. Sunde, J. Schupp and G. Wagner (2011), "Individual Risk Attitudes: Measurement, Determinants and Behavioral Consequences", Journal of the European Economic Association, 9, pp. 522-550.

EBERT, S. (2015), "On skewed risks in economic models and experiments", Journal of Economic Behavior \& Organization, 112, pp. 85-97. 
Ebert, S. And D. Wiesen (2011), "Testing for prudence and skewness seeking", Management Science, 57(7), pp. 1334-1349.

Ebert, S. AND D. Wiesen (2014), "Joint measurement of risk aversion, prudence, and temperance", Journal of Risk and Uncertainty, 48(3), pp. 231-252.

Eckel, C. And P. Grossman (2008), "Men, women and risk aversion: Experimental evidence", Handbook of experimental economics results, 1, pp. 1061-1073.

Eeckhoudt, L. And H. Schlesinger (2006), "Putting risk in its proper place", American Economic Review, 96(1), pp. 280-289.

Filippin, A. And F. Gioia (2018), "Competition and subsequent risk-taking behaviour: Heterogeneity across gender and outcomes", Journal of Behavioral and Experimental Economics, doi: 10.1016/j.socec.2018.05.003.

Gollier, C., J. Hammitt And N. Treich (2013), "Risk and choice: A research saga", Journal of risk and uncertainty, 47(2), pp. 129-145.

Goodman, J., C. Cryder and A. Cheema (2013), "Data Collection in a Flat World: The Strengths and Weaknesses of Mechanical Turk Samples", Journal of Behavioral Decision Making, 26, pp. 213-224.

Haering, A., T. Heinrich and T. Mayrhofer (2017), "Exploring the consistency of higherorder risk preferences", Ruhr Economic Papers, 688.

Halek, M. And J. Eisenhauer (2001), "Demography of risk aversion", Journal of Risk and Insurance, pp. 1-24.

Heinrich, T. And T. Mayrhofer (2018), "Higher-order risk preferences in social settings", Experimental economics, 21(2), pp. 434-456.

Horton, J., D. Rand and R. Zeckhauser (2011), "The online laboratory: Conducting experiments in a real labor market", Experimental Economics, 14, pp. 399-425.

Kahneman, D. And A. TVersky (1972), "Subjective probability: A judgment of representativeness.", Cognitive Psychology.

Kane, A. (1982), "Skewness preference and portfolio choice", Journal of Financial and Quantitative Analysis, 17(1), pp. 15-25.

Kimball, M. (1990), "Precautionary Saving in the Small and in the Large", Econometrica: Journal of the Econometric Society, pp. 53-73.

Kimball, M. (1992), "Precautionary motives for holding assets", in "The new palgrave dictionary of money and finance", In P. Newman, M. Milgate, John Eatwell (Eds.), Stockton Press., pp. $158-161$.

Krieger, M. and T. Mayrhofer (2017), "Prudence and prevention: An economic laboratory experiment", Applied Economics Letters, 24(1), pp. 19-24.

Lajeri-Chaherli, F. (2004), "Proper Prudence, Standard Prudence and Precautionary Vulnerability.", Economics Letters, 82, pp. 29-34.

Maier, J. And M. Ruger (2012), "Experimental Evidence on Higher-Order Risk Preferences with Real Monetary Losses", University of Munich Working Paper. 
Markowitz, H. (1952), "Portfolio selection", The journal of finance, 7(1), pp. 77-91.

Noussair, C., S. Trautmann And G. Van de Kuilen (2014), "Higher order risk attitudes, demographics, and financial decisions", Review of Economic Studies, 81(1), pp. 325-355.

Paolacci, G., J. Chandler and P. Ipeirotis (2010), "Running experiments on Amazon Mechanical Turk", Judgment and Decision Making, 5, pp. 411-419.

RAND, D. (2012), "The promise of Mechanical Turk: How online labor markets can help theorists run behavioral experiments", Journal of Theoretical Biology, 299(21), pp. 172-179.

SchildberG-Hörisch, H. (2018), "Are risk preferences stable?", Journal of Economic Perspectives, $32(2)$, pp. 135-54.

ScotT, R. AND P. Horvath (1980), "On the direction of preference for moments of higher order than the variance", The Journal of Finance, 35(4), pp. 915-919.

SuRI, S. AND D. WATts (2011), "Cooperation and contagion in Webbased, networked public goods experiments", PLoS One, 6(3), pp. 1-8.

Trautmann, S. And G. van De Kuilen (2018), "Higher order risk attitudes: A review of experimental evidence", European Economic Review, 103, pp. 108-124.

TVErsky, A. And D. Kahneman (1981), "The framing of decisions and the psychology of choice", science, 211(4481), pp. 453-458.

Vieider, F., T. Chmura, T. Fisher, T. Kusakawa, P. Martinsson, F. Thompson and A. SundAy (2015a), "Within-versus between-country differences in risk attitudes: implications for cultural comparisons", Theory and Decision, 78(2), pp. 209-218.

Vieider, F., M. Lefebvre, R. Bouchouicha, T. Chmura, R. Hakimov, M. Krawczyk and P. MARTinsson (2015b), "Common components of risk and uncertainty attitudes across contexts and domains: Evidence from 30 countries", Journal of the European Economic Association, 13(3), pp. $421-452$.

von Gaudecker, H., A. Van Soest and E. Wengstrom (2011), "Heterogeneity in Risky Choice Behaviour in a Broad Population", American Economic Review, 101, pp. 664-694.

von Neumann, J. And O. Morgensten (1947), Theory of Games and Economic Behavior, Princeton, NJ: Princeton University Press.

Weber, E., A. Blais And N. Betz (2002), "A Domain-specific Risk-attitude Scale: Measuring Risk Perceptions and Risk Behaviors", Journal of Behavioral Decision Making, 15, pp. 263-290.

WeBer, E. AND C. Hsee (1998), "Cross-cultural differences in risk perception, but cross-cultural similarities in attitudes towards perceived risk", Management science, 44(9), pp. 1205-1217.

Wilcox, N. (2008), "Stochastic Models for Binary Discrete Choice Under Risk: A Critical Stochastic Modeling Primer and Econometric Comparison", Risk Aversion in Experiments: Research in Experimental Economics, 12, pp. 197-292. 


\section{A Appendix: Questionnaire}

\section{Questions on financial risks}

1 You have the opportunity to choose between two hypothetical investments: Option A offers the possibility to gain either $5 \$$ or $15 \$$ with $50 \%$ probability, Option B offers you a sure gain of $10 \$$. Which option do you choose? [A or B]

2 Suppose you have been fined and you have the opportunity to choose between two alternatives. Option A: pay a fine of $10 \$$. Option B: have a $50 \%$ probability of paying either $5 \$$ or $15 \$$. Which option do you choose? [A or B]

3 You may decide to participate to a lottery in which you have the possibility to gain or lose $5,000 \$$ with the same probability of $50 \%$. By choosing Option A you will take part in the lottery, otherwise by selecting Option B you do not participate. Which option do you choose? [A or B]

4 You may decide to take part in a lottery in which you have the possibility to gain or lose $5 \$$ with the same probability of 50\%. By choosing Option A you will take part in the lottery, otherwise by selecting Option B you do not participate. Which option do you choose? [A or B]

5 You have the possibility to choose between two hypothetical options. Option A: you have a $50 \%$ probability of winning or losing $5,000 \$$. Option B: you have a $50 \%$ probability of winning or losing $5 \$$. Which option do you choose? [A or B]

6 You have the possibility to choose between two hypothetical options. Option A: you have a $50 \%$ probability of winning either $5,000 \$$ or $15,000 \$$, Option B offers you a sure gain of $10,000 \$$. Which option do you choose? [A or B]

7 Suppose you have been fined and you have the opportunity to choose between two alternatives. Option A: pay a fine of $10,000 \$$; option B: have a $50 \%$ probability of paying either $5,000 \$$ or $15,000 \$$. Which option do you choose? [A or B]

8 You have the possibility to choose between two hypothetical options. Option A: lose 1,000\$ with a chance in a thousand and 0 otherwise. Option B: pay $1 \$$ for sure. Which option do you choose? $[\mathrm{A} \text { or } \mathrm{B}]^{7}$

9 You have the possibility to choose between two hypothetical options. Option A: $1 \%$ chance to lose $10,000 \$$ and $99 \%$ chance to win $101 \$$. Option B: $50 \%$ probability to win $1,000 \$$ and $50 \%$ to lose $1,000 \$$. Which option do you choose? [A or B]

10 You are asked to choose between two hypothetical options with multiple outcomes. Option A: there is the possibility to gain, with the same chance equal to $33 \%, 0 \$$ or $5,000 \$$ or $10,000 \$$. Option B: there is the possibility to gain, with the same probability of $25 \%, 0 \$$ or $2,100 \$$ or $7,900 \$$ or $10,000 \$$. Which option do you choose? [A or B]

11 You are asked to choose between two hypothetical options with multiple outcomes. Option A: there is the possibility to get, with the same chance equal to $33 \%, 0 \$$ or $5,000 \$$ or $-5,000 \$$. Option B: there is the possibility to get, with the same probability of $25 \%, 2,900 \$$ or $5,000 \$$ or $-2,900 \$$ or $-5,000 \$$. Which option do you choose? [A or B]

\footnotetext{
${ }^{7}$ We decide not to set the same absolute values of Question 8, in which we fix a winning amount equal to a million Dollars, in order to avoid a possible distorting effect: a person who does not have a million Dollars could decide to risk because in any case he/she will not pay the due amount.
} 


\section{Questions on non-financial risks}

- For each of the following statements, please indicate your likelihood of engaging in each activity or behavior. Provide a rating from 1 (Very unlikely) to 5 (Very likely).

- Cheating in an exam;

- evading tax;

- smoking;

- periodically engaging in a dangerous sport;

- exposing yourself to the sun without using sunscreen;

- going on a vacation in third-world country without prearranged travel and hotel accommodation;

- shoplifting a small item (e.g a pen or a lipstick);

- driving your car without fastening seat-belt;

- regularly eating high cholesterol foods.

\section{Overall risk propensity self-assessment}

- How do you see yourself: are you in general a person who takes risk or do you try to evade risk? Please self-grade your choice between 0 (I don't take risk at all) to 10 (I love to take risk).

\section{Socio-demographic questions}

- What is your age?

- What is your gender?

- In which country do you live now?

- What is your marital status?
o SINGLE;
o MARRIED;
o SEPARATED OR DIVORCED;
o WIDOW;
o OTHER.

- Describe the home where you live:
o IT IS OWNED BY YOU;
o IT IS RENTED FOR MONEY;
o IT IS OCCUPIED WITHOUT PAYMENT;
o I LIVE WITH FRIENDS;
o I HAVE NO PERMANENT RESIDENCE.

- How would you define your current labor status? 
o EMPLOYEE;

o SELF-EMPLOYED;

o UNEMPLOYED AND LOOKING FOR A JOB;

o NOT WORKING AND NOT LOOKING FOR A JOB;

o STUDENT/UNPAID EXPERIENCE;

o RETIRED;

o FULFILLING DOMESTIC TASKS;

o OTHER.

- Please choose one of the following that best describe your social class:
o LOWER;
o LOWER-MIDDLE;
o MIDDLE;
o UPPER-MIDDLE;
o UPPER.

- What is your total combined family income before taxes in the last 12 months from all sources?
o LESS THAN 5,000\$;
o $5,000 \$-19,999 \$ ;$
o $20,000 \$-49,999 \$ ;$
o $50,000 \$-149,999 \$$;
o MORE THAN 150,000\$;
o CHOOSE NOT TO ANSWER.

- What is the highest level of education you have completed?
o NO FORMAL EDUCATION;
o PRIMARY EDUCATION;
o LOWER SECONDARY EDUCATION;
o UPPER SECONDARY EDUCATION;
o POST-SECONDARY EDUCATION.

- In the last year, how many times did you go on vacation?
o NONE;
o ONCE;
o TWICE;
o MORE THAN TWICE.

- How old were you 10 years ago? [Control question] 